\title{
O dilema da segurança como realidade fundamental da política internacional: debate teórico e implicações para a América do Sul
}

\section{The Security Dilemma as a Fundamental Reality of International Politics: theoretical debate and implications for South America}

Rev. Bras. Est. Def. v. 7, $\mathrm{n}^{\circ} 1$, jan./jun. 2020, p. 13-42

\section{FLÁVIO PEDROSO MENDES LUCAS P. REZENDE}

\section{INTRODUÇÃO}

Este artigo tem como tema o dilema da segurança, um dos conceitos mais recorrentes e explorados na literatura de política internacional dos últimos 50 anos (Schweller 1996; Glaser 1997; Taliaferro 2000; Collins 2004). A discussão se apoiará no programa de pesquisa científica neorrealista e nos seus desdobramentos internos. A utilidade analítica de algumas das principais lições deste debate teórico será ilustrada pela consideração das dinâmicas políticas de segurança na América do Sul, com foco nas políticas para a cooperação em defesa capitaneadas regionalmente pelo Brasil no século XXI. Isto porque, apesar da existência de uma visão normativa em torno da tentativa de criação de uma comunidade de segurança, Villa (2017) aponta que a região também experimenta reflexos da distribuição de poder regional, tendo, portanto, características de um hibridismo. Nossa proposta neste trabalho é analisar os reflexos do dilema da segurança existente na América do Sul, tal qual sugerido por Villa (2017).

$\mathrm{O}$ artigo subdivide-se, portanto, em duas partes principais, uma teórica e outra empírica. A discussão teórica buscará demonstrar a pervasivida-

Flávio Pedroso Mendes - Professor do curso de graduação e do Programa de Pós-Graduação em Relações Internacionais da Universidade Federal de Uberlândia, possui mestrado em Estudos Estratégicos pela Coppe/UFRJ e doutorado em Relações Internacionais pelo IRI/USP.

Lucas P. Rezende - Professor do curso de graduação e do Programa de Pós-Graduação em Relações Internacionais da Universidade Federal de Santa Catarina. Possui mestrado em Relações Internacionais pela PUC-Minas e doutorado em Ciência Política pela Universidade Federal do Rio Grande do Sul. 
de do dilema da segurança nos relacionamentos políticos internacionais, que não se restringe à mera competição armamentista e tecnológica, perpassando transformações políticas, econômicas e sociais mais complexas. Demonstrar-se-á, por meio de suas principais formulações modernas (Herz 1950; Butterfield 1951; Jervis 1978), a origem sistêmica do dilema da segurança, bem como seu lugar de elo lógico entre os atributos estruturais e as resultantes internacionais no construto teórico waltziano (Waltz 1979). Também será discutida a centralidade do dilema da segurança nos principais debates teóricos do campo da Ciência Política e Relações Internacionais, bem como na clivagem entre realismo defensivo e realismo ofensivo.

A parte empírica tratará da dinâmica sul-americana com vistas a trazer uma análise estrutural da região à luz da concepção do dilema da segurança. Para tanto, em um primeiro momento, será feita uma consideração da balança de poder na América do Sul. O argumento aqui defendido é o de que, entre o início do século e a primeira parte da atual década, a configuração típica da região indicava uma unipolaridade brasileira - o que passa a mudar de forma mais acelerada com o reaparelhamento mais acelerado de outros países, como Colômbia e Chile, e pelo agravamento da crise econômica no Brasil após 2014.

No período da unipolaridade brasileira, houve um largo incremento de medidas cooperativas na área de defesa, resultando em políticas conjuntas de defesa, medidas de monitoramento coletivo, incremento da indústria de defesa e trocas de militares e doutrinas. Muito desse esforço foi institucionalizado pela União de Nações Sul-Americanas (Unasul), em especial pelo seu Conselho de Defesa (CDS) e pelo Centro de Estudos Estratégicos (CEED). Essa dinâmica refletia uma balança de poder favorável ao Brasil.

No entanto, quando o Brasil passa a não mais manter tanto os esforços políticos quanto financeiros da cooperação em defesa, esta começa a se desestruturar e dar espaço a iniciativas unilaterais de reaparelhamento e de cooperação com potências externas. A avaliação empírica busca mostrar que, ainda que seja comum caracterizar a região sul-americana como sendo relativamente pacífica, em comparação com outras regiões do mundo, sua dinâmica política não está imune aos pervasivos efeitos do dilema da segurança.

\section{DILEMA DA SEGURANÇA: O DEBATE TEÓRICO}

O vínculo entre a anarquia do sistema internacional e os efeitos políticos esperados pelo realismo estrutural não é automático, como vários críticos apontaram desde a elaboração da teoria de Waltz (Wendt 1992; Milner 1993). O elo entre o princípio de ordenação e as resultantes sistêmicas só 
pode ser feito mediante a consideração de uma realidade ontológica com que, de acordo com o seu principal elaborador moderno, "as sociedades humanas tiveram de lidar desde o despertar da história” (Herz 1950, 157; tradução nossa). Numa das mais eloquentes caracterizações do fenômeno, Herz define da seguinte forma o dilema da segurança:

Onde quer que tal sociedade anárquica tenha existido - e ela existiu em algum nível na maioria dos períodos da história conhecida - surgiu o que pode ser chamado de "dilema da segurança" de homens, grupos ou seus líderes. Grupos ou indivíduos vivendo em tal constelação devem estar, e geralmente estão, preocupados com sua segurança quanto a ser atacado, subjugado, dominado ou aniquilado por outros grupos ou indivíduos. Esforçando-se por obter segurança quanto a tais ataques, eles são movidos a adquirir mais e mais poder de modo a escapar ao impacto do poder alheio. Isto, por sua vez, torna os demais mais inseguros e os obriga a prepararem-se para o pior. Como ninguém pode jamais sentir-se inteiramente seguro em tal mundo de unidades em competição, segue-se uma competição por poder, e o círculo vicioso de acumulação de segurança e de poder está instalado (Herz 1950, 157; aspas no original; traduzido em Diniz 2002, 13).

O dilema da segurança retrata a situação em que grupos políticos preocupados com sua própria sobrevivência buscam constantemente adquirir meios para garanti-la, incrementando suas capacidades; isso, no entanto, aumenta a insegurança dos demais, temerosos de que os incrementos adicionais dos outros sejam utilizados ofensivamente, e tratam de aumentar suas próprias capacidades para fazer frente à ameaça potencial. Instaura-se uma espiral de incerteza, que acaba por aumentar a insegurança e desconfiança gerais. $\mathrm{Na}$ base lógica do dilema reside uma realidade tática e estratégica relacionada à ambiguidade dos meios de força, ${ }^{1}$ ou seja, ao fato de que as mesmas capacidades militares podem ser usadas tanto para ações ofensivas quanto para fins defensivos. O dilema da segurança fornece a rationale do realismo estrutural e reflete os dois processos pelos quais, de acordo com Waltz (1979), a estrutura do sistema internacional exerce indiretamente os seus efeitos: competição e socialização.

O dilema da segurança tem sua manifestação material mais evidente na dinâmica competitiva de criação, aperfeiçoamento e produção de sistemas de armamentos e de tecnologias que viabilizem o emprego da força (McNeill 1982; O'Connel 1985), porém não se restringe a essa dinâmica. Processos políticos, econômicos e sociais mais amplos podem ser enquadrados analiticamente e compreendidos a partir da lógica do dilema, na medida em que tenham gerado vantagem competitiva a determinados 
grupos políticos e engendrado, em função disso, um processo dinâmico de emulação envolvendo grupos políticos rivais.

Assim, a formação de alianças em sistemas multipolares, um fenômeno político, pode produzir um efeito desestabilizador no sistema internacional por conta da exacerbação do dilema da segurança, simplesmente porque somar potências gera grande potencial, que pode ser empregado para defender ou revisar o status quo (Waltz 1988; Christensen and Snyder 1990). No alvorecer da Europa moderna, a própria constituição e proliferação dos Estados territoriais, percebidos como uma forma organizacional mais eficiente para centralizar e arregimentar os recursos sociais necessários para colocar em campo grandes exércitos, só fazem sentido com um dilema da segurança de alcance continental como pano de fundo. Este é um elemento central dos argumentos construídos por Kennedy (1988) e Tilly (1990). Finalmente, quando a Revolução Francesa "descobriu" o nacionalismo, por acidente ou desígnio, o evidente potencial de uma nação em armas, fornecedora dos insumos para a constituição de exércitos de massa e disposta a sustentar os esforços da guerra em escala continental, restaram poucas alternativas às atônitas e conservadoras cortes europeias senão a implementação gradual de reformas militares, políticas e sociais que transformassem os seus soldados em cidadãos. Nas palavras de Posen:

Eu iria além e especularia que a mobilização do nacionalismo para a guerra ofensiva depende em algum grau da intensidade do "dilema da segurança”, a condição frequente na política internacional em que estados não podem se tornar seguros sem deixar os outros inseguros. Assim, o nacionalismo agressivo deve ser encontrado com mais frequência em estados-nação que encontrem maiores dificuldades em assegurar sua segurança nacional por meios militares mais defensi$\operatorname{vos}^{2}$ (Posen 1993a, 124; aspas no original; tradução nossa).

Uma ressalva importante é que processos políticos, econômicos e sociais, quando afetam o dilema da segurança, só o fazem na medida em que tenham impacto sobre as dinâmicas combatentes. A distinção feita anteriormente entre o elemento mais direto e material do dilema, expresso na competição armamentista e tecnológica, e aspectos conjunturais mais amplos, pode levar à conclusão equivocada de que o dilema se manifesta também em domínios separados do emprego da força. Ocorre que, tudo que pode se converter em um problema de segurança — ou seja, que afete a probabilidade de que um grupo seja destruído ou dominado (Lynn-Jones $1995,664)$ — só o faz se afetar as condições e possibilidades do combate. (Clausewitz 1993, 110; Proença Jr. 2011; Duarte and Mendes 2015). 
Para Herz (1950,; tradução nossa), o dilema da segurança é eminentemente estrutural ${ }^{3}$ e nada tem a ver com uma suposta natureza humana: "se o homem é naturalmente pacífico e cooperativo, ou dominador e agressivo, não é a questão”. Assim, apenas as duas condições pressupostas por Waltz (1979, 121; tradução nossa) em seu processo de teorização - "que a ordem seja anárquica e povoada por unidades que desejem sobreviver" — satisfazem às condições de operacionalidade do dilema da segurança, da forma elaborada por Herz. Ainda segundo Herz (1950), o dilema da segurança é a causa sumarizada do histórico de fracassos dos grandes movimentos sociais e políticos modernos de caráter idealista e transformador. ${ }^{4}$

Contemporaneamente a Herz, Butterfield (1951) trazia outra contribuição ao estudo do dilema da segurança, atribuindo o fenômeno ao que chamou de "medo hobbesiano" e de "pecado universal da humanidade". Contudo, ao retratar o dilema da segurança, Butterfield nega o princípio causal identificado e sugere que se trata de uma resultante não intencionada de origem estrutural:

A maior guerra da história pode ser produzida sem a intervenção de qualquer grande criminoso que deseje deliberadamente fazer mal ao mundo. Ela poderia ser produzida entre duas potências, ambas desesperadamente ansiosas para evitar qualquer tipo de conflito (Butterfield 1951, 19-20; tradução nossa).

Inconsistências à parte, Butterfield é o autor que discute de maneira mais clara uma variável que parece ser central para a discussão do dilema: a existência ou não intenções hostis — ou, colocado de outra forma, se o conflito é real ou ilusório. A ideia é que a competição e, no limite, a guerra, só são frutos de um verdadeiro dilema da segurança se nenhum dos lados envolvidos originalmente tencionava causar danos aos demais, mas o embate não pôde ser evitado em função do círculo vicioso imposto pelo dilema da segurança. Este ponto é enfatizado também por Schweller:

Quando o objetivo de um ou mais Estados é algo além da segurança mútua, o conflito não é aparente, mas real; e por ser real, a consequente insegurança não pode ser atribuída ao dilema da segurança. Os Estados adquirem mais armas não porque interpretam errado os esforços de segurança de outros Estados benignos, mas porque Estados agressivos de fato desejam lhe fazer mal (Schweller 1996, 104; tradução nossa).

Assim, Jervis (2001), ao discutir a Guerra Fria entre Estados Unidos e União Soviética nos termos do dilema da segurança, chega a conclusões ambíguas. Enquanto, para o autor, parte da competição entre as potências dava-se em função de consequências não intencionadas e desnecessárias 
da estrutura de força e da postura da potência rival - processo descrito e explicado por Schelling (1966) —, essa competição dava-se em um contexto político em que o status quo internacional era visto como inaceitável, particularmente pela União Soviética. Jervis chama este tipo de situação de "dilema da segurança profundo" (Jervis 2001, 41; tradução nossa), apesar de que, na acepção de Butterfield (1951) e de Schweller (1996), nestes termos não se poderia caracterizar um verdadeiro dilema da segurança. Este ponto será apreciado abaixo, quando for discutido o realismo ofensivo.

O caráter estrutural do dilema da segurança também fica claro no estudo de Posen (1993b) acerca de conflitos étnicos, que muitos consideram um importante progresso nesta área de pesquisa. Para Posen, o conflito entre grupos étnicos distintos que habitam um mesmo território tem origem no dilema da segurança gerado por uma situação de "anarquia emergente" (Posen 1993b, 27; tradução nossa). Em outras palavras, novas condições de conflito têm lugar a partir do colapso de autoridades centrais em Estados falidos ou impérios desintegrados, o que implica uma alteração progressiva de sua estrutura política doméstica à medida que a anarquia substitui a hierarquia como princípio de ordenação. Grupos étnicos previamente submetidos a um governo central, capaz de regular o uso da força entre eles, veem-se de repente num "estado de natureza" e de autoajuda, responsáveis por prover suas próprias condições de sobrevivência. Neste estudo, Posen (1993b) desenvolve e testa a tese, aludida anteriormente (Posen 1993a), de que o nacionalismo se torna um instrumento nas mãos daqueles que precisam mobilizar recursos sociais de poder para fazer frente a ameaças externas.

Um terceiro trabalho fundacional e de enorme influência sobre o dilema da segurança foi elaborado por Jervis (1978). Nele, Jervis se preocupa menos com a caracterização do dilema do que com a possibilidade de sua mitigação. Para Jervis, o dilema da segurança também tem origem estrutural: ${ }^{5}$

[C]entral ao argumento sobre o dilema da segurança é que o aumento da segurança de um Estado pode tornar os outros menos seguros não por percepção errada ou hostilidade imaginada, mas por conta do contex to anárquico das relações internacionais (Jervis 1978, 76; tradução nossa).

Segundo Jervis, entretanto, a intensidade do dilema da segurança não é universal e varia em função de fatores geográficos e tecnológicos, na medida em que eles alterem um suposto balanço entre o ataque e a defesa. Em linhas gerais, se num determinado contexto material o lado que defende possui vantagens sobre o lado que ataca, o dilema da segurança perderia parte de sua importância como constrangimento à ação dos Estados. Isso se daria porque um incremento de poder por parte de um 
Estado potencializaria mais sua capacidade de defesa do que de ataque, e, portanto, poderia ser compensado por um investimento proporcionalmente menor por parte de outro Estado que apenas queira restituir sua margem de segurança, gerando uma progressão decrescente que tende ao equilíbrio. Porém, se o ataque apresentar vantagens sobre a defesa, segue o argumento, dar-se-ia o inverso: um incremento de poder potencializaria mais o ataque do que a defesa, levando outro Estado que apenas queira restituir sua margem de segurança a realizar um investimento proporcionalmente maior, gerando uma progressão ascendente sem ponto lógico de chegada. ${ }^{6}$ O dilema da segurança assumiria grande intensidade e a competição seria máxima ${ }^{7}$ (Jervis 1978, 186-214).

Para muitos autores, o dilema da segurança também está no centro de uma das principais clivagens na teoria das Relações Internacionais das últimas décadas: o debate intraprogramático ${ }^{8}$ entre realismo defensivo e realismo ofensivo. A clivagem tem como ponto de partida os efeitos da anarquia sobre o comportamento estatal e a dinâmica da competição pelo poder: os Estados se esforçam para maximizar poder ou simplesmente para manter sua posição relativa no sistema? Acredita-se que a proposição defensiva tenha se originado da perspectiva seminal do próprio Waltz:

Em contraste [com o realismo clássico de Morgenthau], o neorrealismo vê o poder como um fim possivelmente útil, e os Estados correm riscos se possuírem poder de menos ou em demasia. Fraqueza excessiva pode incentivar um ataque de um adversário, que de outra forma teria sido dissuadido por uma força maior. Força excessiva pode levar os outros Estados a aumentarem suas armas e a somarem seus esforços contra o Estado dominante. Porque o poder é um meio possivelmente útil, estadistas razoáveis buscam tê-lo em quantidade apropriada. Em situações cruciais, entretanto, a preocupação suprema dos Estados não é com o poder, mas com segurança. Esta revisão é importante (Waltz 1988, 616; tradução nossa).

De sua parte, o realismo ofensivo, capitaneado pela teoria de política das grandes potências de Mearsheimer (2001), pressupõe que o principal caminho para a maximização das condições de sobrevivência de um Estado é pela maximização gradual e calculada de poder. ${ }^{9}$

A diferença de pressupostos das duas perspectivas, naturalmente, tem impacto direto sobre suas expectativas quanto às possibilidades de cooperação internacional e à viabilidade de se contornar ou mitigar o dilema da segurança. Assim, Jervis (1999) propõe entender a clivagem realismo defensivo $\mathrm{x}$ ofensivo em termos da fronteira de eficiência paretiana: para os realistas defensivos, posto que parte da competição internacional é desnecessária 
por ser fruto não de intenções revisionistas, mas da incerteza gerada pelo potencial ofensivo das posturas de força, o nível de cooperação interestatal estaria fora da fronteira de Pareto, e, portanto, haveria espaço para o aprimoramento geral; ${ }^{10}$ para os realistas ofensivos, os Estados já se encontrariam na fronteira, podendo aprimorar sua posição apenas em detrimento dos demais. Para Taliaferro (2000), mesmo considerando a inevitabilidade do dilema da segurança, os realistas defensivos ainda acreditariam na possibilidade de controlar a intensidade da competição internacional por meio de "modificadores estruturais" (Taliaferro 2000, 137; tradução nossa), sendo o principal deles o já mencionado balanço tecnológico entre ataque e defesa. ${ }^{11}$

Também se tornou comum diferenciar as duas abordagens em termos da ênfase dada à possibilidade ou à probabilidade de conflito. Para o realismo ofensivo, as grandes potências enxergam umas às outras como revisionistas sedentas por poder e sempre esperam o pior das capacidades alheias - o que é possível é o que importa. Para o realismo defensivo, de acordo com o argumento, os Estados reconheceriam que parte do medo e da desconfiança no sistema internacional é infundada, não sendo, assim, levados a equalizar de maneira absoluta capacidades com ameaças: é a probabilidade de emprego da força, em relacionamentos e contextos específicos, que influenciaria o comportamento estatal (Brooks 1997; Tang 2008).

Com efeito, toda a base lógica do realismo defensivo depende de que parte significativa da competição internacional por segurança se deva a consequências não intencionadas de posturas originariamente defensivas - ou seja, depende do elemento de dilema no dilema da segurança. No entanto, como lembra Schweller (1996), parece faltar o impulso que colocaria as engrenagens em movimento. Afinal, se todas as grandes potências querem apenas se defender, o que elas temem? Qual é a causa imediata do dilema da segurança? Portanto, para que a espiral do dilema da segurança seja ativado é preciso que ao menos algumas potências possam não ser de fato conservadoras - ou que possam deixar de sê-lo em algum momento. Jervis complica ainda mais as coisas ao reconhecer que a fronteira entre revisionismo e preservação pode ser mais tênue do que se imagina:

Para se proteger, os Estados buscam controlar, ou ao menos neutralizar, áreas em suas fronteiras. Mas as tentativas de estabelecer zonas-tampão podem alarmar os outros que tenham interesses lá, os quais temem que precedentes indesejáveis sejam criados ou acreditam que sua própria vulnerabilidade será aumentada. Quando tampões são buscados em áreas desprovidas de grandes potências, a expansão tende a se retroalimentar para proteger o que é adquirido, como era frequentemente apontado por aqueles que se opunham à expansão colonial (Jervis 1978, 169; grifo e tradução nossos). 
A existência ou não de um efetivo dilema da segurança na política internacional, aparentemente, poderia apresentar um elemento concreto e discernível para diferenciar as duas vertentes do realismo. Para Snyder (2002), se a noção de um dilema da segurança se refere à trágica situação em que Estados se armam apenas para se defender, mas acabam, inadvertidamente, por instaurar uma dinâmica competitiva que diminui a segurança de todos, então esta ideia estaria completamente perdida no universo político do realismo ofensivo. No modelo de Mearsheimer, apesar de se armarem para garantir sua própria sobrevivência, os Estados veem na agressão e expansão de seu poder relativo a melhor forma de consegui-lo. Portanto, se os Estados temem o pior a partir do fortalecimento dos demais, tal temor é coerente com as intenções que levaram os últimos a incrementarem suas capacidades, deixando de caracterizar um dilema da segurança para retratar uma simples competição por segurança (Snyder 2002).

O problema, no entanto, é que isso não é reconhecido pelo próprio Mearsheimer, para quem "[o] 'dilema da segurança', um dos mais conhecidos conceitos na literatura de Relações Internacionais, reflete a lógica básica do realismo ofensivo" (Mearsheimer 2001, 35-6; aspas no original; tradução nossa). Mas será possível conciliar o entendimento original do dilema da segurança com o quadro da política internacional pintado pelo realismo ofensivo?

Considerando que Mearsheimer parte do pressuposto waltziano fundamental da maximização das condições de sobrevivência, pode-se argumentar que o elemento de dilema no dilema da segurança não deixa efetivamente de existir no realismo ofensivo, mas antes é apenas deslocado. Se maior segurança implica aumento de poder, e sendo os recursos de poder finitos e divisíveis, então a competição por segurança se confunde com a competição por esses recursos de poder, convertendo-se, portanto, num jogo de soma zero. Assim, aumento de segurança para um necessariamente significa decréscimo de segurança para outro(s), o que é a essência do dilema. Afinal, não é possível que todos aumentem seu poder relativo ao mesmo tempo. A diferença agora diz respeito simplesmente às possibilidades de arrefecimento da dinâmica: realistas defensivos acreditam que o dilema pode ser mitigado ou eliminado, ao passo que a rationale proposta pelo realismo ofensivo prevê que o dilema da segurança seja inerentemente inescapável e severo. ${ }^{12}$

Para concluir a presente discussão teórica do dilema da segurança e sumarizar suas principais lições, é útil explorar uma formulação mais recente proposta por Tang (2010), que buscou sintetizar os elementos contidos nas discussões seminais de Butterfield, Herz e Jervis. Segundo Tang, a formulação BHJ — em referência às iniciais dos nomes dos referidos autores - 
apresenta oito aspectos que, somados, retratariam por completo o dilema da segurança e suas implicações. São eles:

i. A origem do dilema da segurança é a natureza anárquica da política internacional;

ii. Sob anarquia os Estados nunca podem estar certos quanto às intenções presentes e futuras dos demais, o que gera um temor compartilhado;

iii. O dilema da segurança tem origem não intencional (os Estados envolvidos querem apenas segurança, e não intencionalmente ameaçar os outros);

iv. Diante do medo e da incerteza, os Estados acumulam capacidades para se defender, as quais inerentemente apresentam atributos ofensivos;

v. As dinâmicas do dilema da segurança se reforçam e frequentemente geram espirais negativas e não intencionais, tais como corridas armamentistas;

vi. As dinâmicas do dilema da segurança tornam contraprodutivas algumas medidas de segurança - como o acúmulo excessivo de capacidade militar;

vii. O círculo vicioso do dilema da segurança pode trazer resultados trágicos, como guerras que seriam, em princípio, evitáveis;

viii. A intensidade do dilema da segurança é regulada por fatores materiais e psicológicos (Tang 2010, 39-40).

Ao tempo em que oferece um ponto de partida útil para a discussão do dilema da segurança, a síntese proposta por Tang precisa ser problematizada, o que foi feito por Mendes (2013). Contudo, para nosso propósito neste artigo, o principal fator material que o realismo estrutural traz à mesa para a apreensão do dilema da segurança é a distribuição de capacidades no interior do sistema internacional — ou, em outras palavras, como diferentes polaridades induzem a comportamentos distintos para lidar com o dilema. Este tema será tratado na próxima seção, em conjunto com o objeto empírico do artigo.

\section{O DILEMA DA SEGURANÇA E A COOPERAÇÃO EM DEFESA}

Ao discorrer sobre a cooperação em defesa, Rezende (2014; 2015) afirma que se os Estados tiverem a cooperação em defesa como um meio de maximizarem o seu poder, aumentando a sua capacidade de sobrevivência, devem atentar para as seguintes variáveis: (1) a distribuição de recursos 
entre as unidades do sistema; (2) o tipo de cooperação; (3) o efeito da cooperação na capacidade estatal; (4) o desenho das instituições geradas; (5) a emulação de casos bem-sucedidos.

Para compreender a dinâmica sul-americana recente, é importante que compreendamos os incentivos sistêmicos pelos quais a região passou desde o início do século XXI. Nossa premissa é que a região experimentou dois tipos de polaridade: a unipolaridade brasileira, do início do século até o final do primeiro mandato de Dilma Rousseff, e uma transição à multipolaridade desequilibrada no segundo mandato de Dilma Rousseff, no governo de Michel Temer e início do de Jair Bolsonaro.

Sobre a primeira variável do modelo, para o sistema global, o suposto é que haja a unipolaridade. A impossibilidade do contrabalanceamento levará os demais atores do sistema, se desejarem maximizar a sua segurança, a não se oporem diretamente aos interesses da potência unipolar. Estando a balança de poder global definida, as balanças de poder regionais terão maior importância para a compreensão da cooperação em defesa sob a unipolaridade.

Outras polaridades terão outros incentivos sistêmicos diferentes. $\mathrm{Na}$ bipolaridade, esse incentivo previamente descrito existirá apenas para os membros das alianças de cada um dos polos, separadamente, e de modo a se oporem mutuamente. Na multipolaridade, seja ela equilibrada ou desequilibrada, os efeitos sistêmicos indicarão a cooperação em defesa dentro do modelo tradicional das alianças, tal qual descrito pela teoria clássica da balança de poder.

No caso de países com baixas capacidades, renunciar a um mínimo de autonomia pode representar dar fim à própria sobrevivência desses Estados. Seria o caso de multipolaridades equilibradas, em que a capacidade estatal é quase nula. Poderíamos, para evitar confusões com as dinâmicas da multipolaridade equilibrada, chamar esses casos de nulidade polar. Aqui, não há polos claros no sistema, devido à baixa capacidade dos Estados envolvidos.

De igual modo, quando a distribuição de recursos for excessivamente assimétrica na balança de poder regional, a cooperação em defesa pode significar a perda total de autonomia dos Estados vulneráveis frente aos principais polos do sistema regional. Esse é o caso das multipolaridades desequilibradas. Cooperar em segurança, nesses casos, seria sinônimo de incentivar o candidato a hegêmona regional em sua empreitada - desestabilizando ainda mais o sistema e, por parte dos demais atores envolvidos, diminuir, e não aumentar, a sua capacidade de sobrevivência - o que iria contra as expectativas do realismo ofensivo. Sob a perspectiva da potência unipolar, a multipolaridade desequilibrada é o mais arriscado modelo de balança de poder, uma vez que há um candidato a hegêmo- 
na regional que, se bem-sucedido, pode incomodá-la na balança de poder global. Nesse sentido, nas balanças de poder regionais, a nulidade polar $e$ a multipolaridade desequilibrada são os modelos que não incentivam estruturalmente a cooperação em defesa.

Tal qual na balança de poder global, os sistemas que mais estimulam a cooperação em defesa nas balanças de poder regionais são a bipolaridade, uma vez que forma dois grandes blocos de alianças, e a unipolaridade, que, tal qual no sistema global, leva os demais atores a se alinharem naturalmente com o polo regional — já que não há a possibilidade de uma aliança balanceadora.

Há uma diferença marcante, contudo, da cooperação nas balanças de poder regionais e a global. Ao tratarmos das dinâmicas regionais sob a unipolaridade, a configuração regional multipolar equilibrada pode também incentivar a cooperação em defesa - diferentemente do que é visto na balança de poder global. Essa distribuição de poder pode servir como ferramenta para os Estados engajados na cooperação em defesa para: (i) conter o surgimento de um candidato a hegêmona regional. A accountability e a troca geral de informações possibilitaria os atores a identificarem a emergência de revisionistas. Na eventualidade de um Estado concentrar sobremaneira os ganhos da cooperação, a lógica da preocupação com os ganhos relativos levará à formação de uma aliança balanceadora para a contenção do candidato a hegêmona regional, reestabilizando o sistema pela lógica da balança de ameaças (Walt 1987; Dyson 2010; Resende-Santos 2007). Essa possibilidade, de maior influência das balanças de poder regionais, será maior nos casos de desengajamento (Monteiro 2011/12) ou de maior desinteresse da potência unipolar na região. Caso a aliança falhe, ou se mostre fraca demais, sempre existe o recurso à potência unipolar de agir como balanceador offshore, uma vez que trabalhará sempre de forma a evitar o surgimento de outro hegêmona regional; (ii) aumentar o grau da capacidade estatal geral das unidades envolvidas. Se, sob cooperação, todas aumentam em proporção semelhante os seus recursos, não há um aumento do dilema da segurança dessas unidades no plano regional, e sua posição relativa frente à potência unipolar global é incrementada. Contanto que esse aumento de recursos não represente uma tentativa de formação de uma aliança balanceadora no plano global — o que é pouco provável, se não impossível, na unipolaridade - tal incremento relativo não tem motivos para levar à oposição da potência unipolar global. Os atores, por motivos do realismo ofensivo, cooperam sob a multipolaridade equilibrada para aumentarem a sua capacidade de sobrevivência frente tanto à potência unipolar global quanto frente aos demais atores dos sistemas global e regional.

Jervis (1978) afirma que mesmo as potências do status quo podem, em algum momento, ver-se insatisfeitas com ele e resolver alterá-lo, ameaçan- 
do os demais Estados protegidos pela ordem vigente - o que justifica a preocupação dos demais Estados em buscarem aumentar a sua segurança frente à potência unipolar — ainda que isso não seja suficiente para um balanceamento em curto ou médio prazo.

\section{A BALANÇA DE PODER E O DILEMA DE SEGURANÇA NA AMÉRICA DO SUL NO SÉCULO XXI}

Na América do Sul não existe nenhum país que seja uma grande potência global. Nenhum deles tem, ou já teve acesso, a armas de destruição em massa (ADM). Tampouco algum detém o próprio controle do espaço. Nem mesmo têm capacidade (nuclear ou convencional) de segundo ataque ou capacidade de inexpugnabilidade mútua contra um ataque de alguma grande potência global. Ou seja: a América do Sul é uma região de baixa concentração relativa de recursos, onde não há um candidato a hegêmona global.

Rezende $(2014 ; 2015)$ avalia quinze indicadores diferentes para definir a polaridade sul-americana. Os estudos passam por indicadores que vão desde aspectos gerais, como tamanho da população, do PIB e os investimentos em defesa; por indicadores materiais, como a quantidade de efetivos e análise dos meios operacionais disponíveis; e por indicadores específicos para a mensuração de poder, como os Correlates of War (COW) e o índex Global Fire Power. Contudo, há dados divergentes em diversos deles, apontando em direção a diferentes tipos de polaridades, ora indicando tendências a uma unipolaridade, ora indicando tendências a uma multipolaridade desequilibrada.

Segundo o autor, em indicadores importantes e amplamente tidos como válidos para a mensuração do poder militar dos Estados, havia uma configuração de poder tipicamente unipolar na América do Sul na primeira década e meia do século XXI. Na análise do tamanho das populações, Rezende aponta o quão desproporcional é o tamanho da população brasileira em comparação com a do resto dos países sul-americanos, equivalente a mais do que o de todos os demais países sul-americanos somados. Esse é um elemento importante de poder, em especial em países com recursos energéticos, plantas industriais desenvolvidas e disponibilidade de crédito. O Brasil, mais do que qualquer outro país na região, concentra tais atributos, o que faz com que a sua ampla população fortaleça o seu potencial de poder militar. Esse indicador, associado a outros fatores, como o potencial energético da camada do pré-sal, mostram a distância que o Brasil tem, em relação aos demais vizinhos, em termos de independência de recursos vindos de fora. Segundo Oliveira (2012, 222), as reservas do pré-sal brasileiro "podem chegar a até 100 bilhões de barris de petróleo e gás equivalente", 
o que, associado às suas outras fontes energéticas já em operação - hidrelétricas, termoelétricas e termonucleares - dá ao Brasil, mais do que qualquer outro país da América do Sul, um potencial energético ímpar, conferindo-lhe maior capacidade de transformar poder latente em poder real, nos termos de Mearsheimer (2001).

A análise do tamanho do PIB, quando associada ao tamanho da população, é ainda mais reforçadora de uma tendência à unipolaridade brasileira. Em especial a partir de 2007, Rezende (2014; 2015) aponta uma concentração de recursos nas mãos do Brasil que supera, em larga medida, os PIBs somados de todos os demais Estados sul-americanos. A tendência observada era, até 2013 , de uma continuidade desse crescimento brasileiro e de uma manutenção no PIB dos demais países, o que reforçaria o Brasil como polo único econômico na América do Sul.

Outro importante indicador de mensuração de poder, os Correlates of War (COW), amplamente utilizados para medir o poder militar, também indicavam uma unipolaridade brasileira até meados dos anos 2010 (Lima 2013). O problema apontado por Wohlforth (1999, 17; tradução nossa) para os COW "é o seu suposto implícito de que as fontes do poder nacional não mudaram desde o alvorecer da era industrial”. No caso dos Estados sul-americanos, os Correlates of War talvez sejam ainda mais significativos do que para as grandes potências para a mensuração regional de poder relativo, uma vez que os primeiros se encontram ainda em um estágio de desenvolvimento menos avançado do que os últimos - são todos considerados países em desenvolvimento na América do Sul. Ainda que favoreça países com grande território e grande população, essa é uma das demandas que Mearsheimer (2001) coloca para que um Estado possa ser candidato a grande potência. Logo, permanece importante como indicador de poder desde que não considerado de forma isolada.

Quando incorporados também os gastos militares, em conjunto com os COW e o PIB, para pegarmos os mesmos indicadores utilizados por Wohlforth (1999; 2009), vemos, tal qual no caso estadunidense, que o Brasil é o único país sul-americano a se destacar entre os demais. Os dados referentes aos anos de 2007 e 2013, respectivamente ano intermediário de análise e último ano antes do início da crise brasileira, confirmam a unipolaridade regional no período. O Brasil, que era líder isolado já nos gastos em defesa, foi o país que, percentualmente, mais aumentou os seus gastos no setor - o que fez com que aumentasse a sua distância frente aos demais. Os gastos brasileiros em defesa superam o de todos os demais países sul-americanos somados, mesmo que se leve em consideração o aumento dos gastos em defesa promovidos pela Colômbia nos últimos anos. Fazendo uso, portanto, da mesma metodologia utilizada por Wohlforth 
(1999; 2009) para justificar a unipolaridade estadunidense, de simetria na concentração sobremaneira do PIB, COW e gastos militares, não teríamos outra conclusão senão a de que o Brasil é uma potência unipolar na América do Sul. Os Gráficos 1 e 2 apresentam o percentual de concentração de poder em relação ao hegêmona, baseado na metodologia utilizada por Wohlforth (1999; 2009), para Brasil, Argentina, Colômbia e Venezuela nos anos de 2007 e $2013 .^{13}$

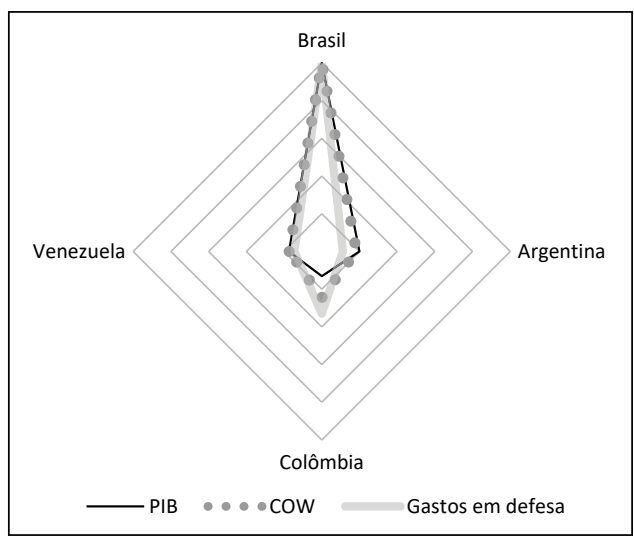

Gráfico 1 - Percentual de poder em relação ao hegêmona na América do Sul em 2007.

Fonte: Rezende (2015).

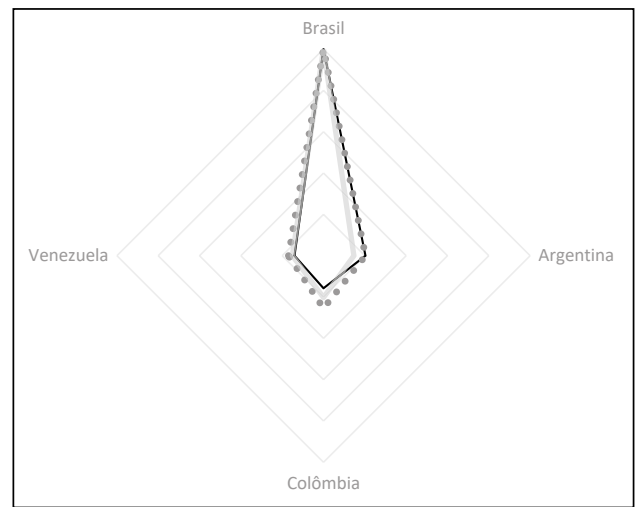

Gráfico 2 - Percentual de poder em relação ao hegêmona na América do Sul em 2013.

Fonte: Elaborado pelos autores com base em dados de IISS (2014) e Mijares (2016). 
Quando fazemos uma análise dos recursos militares disponíveis para uso imediato, todavia, o que Mearsheimer (2001) chama de poder real, tanto em comparação de número geral de efetivos quanto de meios operacionais, vemos que não havia indícios de uma unipolaridade brasileira. No total de efetivos nas FFAA, a partir dos anos 2000, o enorme crescimento da Colômbia a aproxima muito do Brasil - o que faz com que a superioridade numérica brasileira, que já não era absoluta na década de 1990, ficasse ainda menor. Quando analisamos os totais de efetivos das Marinhas, vemos que essa tendência se repete, com intensidade um pouco menor, mas mostrando o grande avanço colombiano nos anos recentes - em especial, em 2013. Mas são os efetivos totais dos Exércitos que mais demonstram problemas à hipótese da unipolaridade brasileira. A partir de 2009, o Exército colombiano supera, com números expressivos, o brasileiro. Apenas os totais das Forças Aéreas é que demonstram uma superioridade brasileira frente aos seus vizinhos. Contudo, a soma dos demais países supera os números do Brasil — o que o deixa com uma concentração alta, mas não indica tendência a uma unipolaridade (Rezende 2014; 2015).

Ao passarmos para a análise dos meios operacionais, temos conclusões mais próximas às dos totais de efetivos do que dos indicadores gerais de poder. Rezende (2014; 2015) afirma que na soma dos veículos blindados, o Brasil fica à frente dos demais, mas não detém mais que a soma dos outros países sul-americanos. $\mathrm{O}$ mesmo se dá na análise das peças de artilharia, nas embarcações de águas azuis e nos aviões de combate. Na avaliação do número de submarinos, o Brasil não apenas não tem vantagem frente aos demais, mas é superado pelo Peru. O mesmo se dá na avaliação das embarcações de águas marrons, na qual o Brasil é superado, uma vez mais, tal qual no total dos Exércitos, pela Colômbia.

Baseados nos pontos supramencionados, concluímos que a balança de poder na América do Sul encontrava-se em um momento de transição entre uma unipolaridade e uma multipolaridade desequilibrada — um sistema bastante instável. Isso porque, como em uma multipolaridade desequilibrada, há um candidato a polo que ainda não se consolidou como tal de forma definitiva. Há espaço para questionamento, dado que sua superioridade não é absoluta, o que pode ser convidativo a Estados revisionistas. Mas, tal qual em uma unipolaridade, o Brasil, por vezes, age como provedor de bens coletivos, em especial, via cooperação em defesa. É neste sentido que a cooperação em defesa na região sobe e desce (Rezende, 2014; 2015) ${ }^{14}{ }^{4}$

A erosão do sistema interamericano de defesa, em conjunto com o surgimento das novas ameaças e as dinâmicas da unipolaridade global, fizeram surgir na América do Sul e em outras regiões não críticas uma percepção 
normativa para a integração regional (Cepik 2010; Fuccille and Rezende 2013), o que está em linha com a expectativa da unipolaridade regional.

É nesse cenário que a União de Nações Sul-Americanas (Unasul) foi criada, em 2008, por iniciativa do Brasil, congregando todos os doze países independentes da América do Sul. ${ }^{15}$ A decisão de excluir os Estados Unidos e fazer um alinhamento exclusivamente dos doze países sul-americanos buscava uma abordagem diferente daquela feita na Organização dos Estados Americanos (OEA), aumentando o poder de barganha e autonomia política para aumentar o reconhecimento dos objetivos específicos da América do Sul. Nesse sentido, a Unasul não se colocava em posição contrária aos EUA ou à OEA, mas vem no sentido de complementar o alinhamento sul-americano de defesa (Cepik 2010). ${ }^{16}$

A criação do Conselho de Defesa Sul-Americano (CDS) demandou um pouco mais de esforço, devido à oposição inicial por parte da Colômbia. Segundo Cepik (2010), a discussão do CDS foi o assunto mais polêmico nas negociações do Tratado Constitutivo da Unasul. O receio era que ele consolidasse um imperialismo brasileiro na região. Por esforços do Brasil, tais dificuldades foram superadas (Fuccille and Rezende 2013). É importante frisar que tanto a Unasul quanto o CDS foram fruto de uma iniciativa brasileira em costurar tais arranjos e arcar com grande parte de seus custos - tanto políticos quanto monetários. E, ainda que seja um arranjo relativamente novo, atingiu, logo nos primeiros anos, alguns resultados significativos (Battaglino 2009; Fuccille and Rezende 2013; Torres and Gomes 2012).

Segundo Rezende (2014; 2015), foi vital a participação da Unasul-CDS em um momento em que a política externa brasileira (PEB) refletia as pressões sistêmicas da unipolaridade do Brasil na América do Sul, na solução de crises como a que envolveu Colômbia, Equador e Venezuela, em 2008; na crise doméstica que ocorreu na Bolívia, também em 2008, que ameaçava fragmentar o país; na solução para a crise hondurenha, que depôs o presidente Manuel Zelaya, em 2009; e no apoio para a solução do quase-golpe no Equador, em 2010, para tentar depor o presidente Rafael Correa. Todas essas crises apontavam para um sucesso quase que instantâneo da Unasul e do CDS, trazendo uma percepção otimista para as recém-criadas instituições, como ressalta Serbin (2009).

Por outro lado, em anos mais recentes, o Brasil foi bem menos protagônico, o que esvaziou a importância da Unasul e do CDS em crises como, por exemplo, a do Paraguai, em 2012, que depôs, em menos de 24 horas, o presidente Fernando Lugo; a crise entre Brasil e Bolívia, em 2013, quando o diplomata brasileiro Eduardo Saboia levou, sem o consentimento do então ministro das Relações Exteriores do Brasil, Antonio 
de Aguiar Patriota, o ex-senador boliviano Roger Pinto Molina para o território brasileiro; a crise institucional venezuelana após a morte de Hugo Chávez, sobre quem assumiria a presidência da República e o processo eleitoral que se seguiu no país; ou na resposta da América do Sul à crise financeira global, iniciada em 2008 e ainda em curso. Em todos esses eventos, não apenas o papel brasileiro foi questionado, como suas decisões não levaram a uma aproximação maior na região, mas a um distanciamento, o que enfraqueceu, ao invés de fortalecer, a Unasul e o CDS. Este esvaziamento, segundo Vaz, Fuccille e Rezende (2017), em especial devido ao distanciamento brasileiro, foi agravado após o impeachment de Dilma Rousseff em 2016, culminando na retirada do Brasil em definitivo da Unasul, já no governo de Jair Bolsonaro, acompanhado de Argentina, Chile, Colômbia, Equador, Guiana, Paraguai e Peru.

No processo de desconstrução da Unasul, o papel vacilante do Brasil também levou a um papel vacilante das novas instituições cooperativas fiadas por ele, refletindo as instabilidades típicas de uma multipolaridade desequilibrada. A impossibilidade de uso da mesma metodologia para avaliar a concentração de poder regional pós-2013 nos impede de apontar aqui, materialmente, o fim da tendência à concentração de poder no Brasil vista na primeira década e meia dos anos 2000. ${ }^{17}$ No entanto, a crise político-econômica brasileira, iniciada em 2014, ainda sob o governo de Dilma Rousseff, segue ainda em curso, tendo perpassado o governo Temer e o início do governo Bolsonaro, o que contribuiu tanto para o desengajamento brasileiro na região quanto para a percepção, tanto pelo próprio Brasil quanto pelos vizinhos, de uma diminuição da posição privilegiada relativa que o país tinha na América do Sul, precipitando, por razões domésticas, explicadas pelo realismo neoclássico em Vaz, Fuccille e Rezende (2017), uma dinâmica regional típica de uma multipolaridade desequilibrada.

As dificuldades relacionadas à cooperação em defesa na América do Sul colocadas acima têm origens variadas. Mas não se pode deixar de trazer um elemento importante: o político. A América do Sul é composta por Estados soberanos que, segundo o realismo ofensivo, buscam, acima de qualquer coisa, a sua sobrevivência. Motivados pelo medo de uma retomada da unipolaridade na região, os demais países, preocupando-se com a sua sobrevivência, nutrem um receio compreensível de uma consolidação do Brasil como polo regional, o que prejudicaria a autonomia soberana do resto dos países sul-americanos. Esta preocupação regional com o tamanho do Brasil sempre existiu, e esteve presente mesmo sob o período unipolar brasileiro, como visto nos (breves) anos de ouro da Unasul, com alguma resistência dos vizinhos a aceitar a liderança do Brasil fora da esfera regional (Malamud 2011). 
No entanto, Amorim Neto (2011) mostra bem como o Brasil, historicamente, responde às pressões sistêmicas, atuando com maior protagonismo internacional quando detém mais recursos e de forma mais retraída quando tem menos recursos. O Brasil, durante a primeira década do século XXI, com destaque para o governo Lula e o primeiro mandato de Rousseff, agiu como potência unipolar, arcando com os custos de construção e manutenção de regimes de cooperação em defesa sul-americanos, como o CDS, e, em um cenário mais amplo de integração regional, a Unasul. Ademais, projetos de reestruturação das Forças Armadas brasileiras, como a construção do primeiro submarino de propulsão nuclear da América do Sul, a compra dos caças FX-2 e o projeto de construção de um porta-aviões em parceria com a Rússia podem fazer a diferença, nos anos vindouros, e consolidar a unipolaridade brasileira na América do Sul. Todavia, o mesmo incentivo não foi continuado pelo governo de Dilma Rousseff, em especial a partir de 2014, com o acirramento da crise econômica brasileira, sendo radicalmente alterado a partir do governo Temer que, desde o seu início como interino, mostrou uma inflexão ainda maior ao reorientar as relações Sul-Sul dos governos petistas para uma Norte-Sul, buscando parcerias com os EUA e Europa e se distanciando dos fóruns regionais. Mudou também o tom de como o Brasil se relaciona com os países sul-americanos, e a resposta foi imediata. $\mathrm{O}$ ambiente de estabilidade que se mostrava na unipolaridade deu lugar a um de instabilidade e crises, ainda que mais retóricas do que militares, entre o Brasil e outros países da América do Sul, como Venezuela, Bolívia, Equador e Uruguai, em um comportamento típico da mais instável distribuição de poder, a multipolaridade desequilibrada (Vaz, Fuccille, and Rezende 2017).

O governo de Jair Bolsonaro seguiu e aumentou o desengajamento iniciado no governo pregresso, aderindo, por vezes retoricamentente, ao antiglobalismo do governo de Donald Trump, nos EUA, e jogando a pá de cal na existência dos arranjos multilaterais criados e mantidos pelo Brasil nos anos de tendência unipolar. É ainda cedo para afirmar se novas iniciativas regionais emergirão com a mesma força, como o Prosul, assinado na Declaração de Santiago, em março de 2019, em conjunto com Argentina, Chile, Colômbia, Equador, Guiana, Paraguai e Peru, e se refletirão uma consolidação da multipolaridade (mantendo-os fracos e com poucos resultados expressivos) ou uma retomada da unipolaridade brasileira (repetindo o que se viu com a Unasul previamente).

Concluímos aqui, portanto, que a América do Sul reproduz as expectativas do dilema da segurança, o que nos coloca próximos às conclusões também neste sentido de Villa (2017), que enfatiza que a região experimenta um hibridismo de aspectos políticos ligados à tentativa de criação 
de uma comunidade de segurança e aspectos ligados ao equilíbrio de poder. Durante a unipolaridade do Brasil, pudemos perceber o aumento de medidas cooperativas na área de defesa, levando a políticas conjuntas, medidas de monitoramento coletivo, aumento da indústria de defesa e trocas de militares e doutrinas. Esse esforço foi institucionalizado pela Unasul e pelo CDS. Essa dinâmica refletia uma balança de poder favorável ao Brasil.

Contudo, a partir da crise econômica brasileira e da manutenção do incremento militar de Colômbia e Chile, o Brasil passou a não mais manter tanto os esforços políticos quanto financeiros da cooperação em defesa, levando a uma rápida desestruturação dessas instituições e dando espaço a disputas regionais, em um reflexo da brevidade do período unipolar brasileiro. Logo, ainda que seja comum caracterizar a região sul-americana como sendo relativamente pacífica em comparação com outras regiões do mundo, sua dinâmica política não está imune aos pervasivos efeitos do dilema da segurança.

\section{REFERÊNCIAS}

Amorim Neto, Octavio. 2011. De Dutra a Lula. A condução e os determinantes da política externa brasileira. Rio de Janeiro: Elsevier. Battaglino, Jorge. 2009. "O Brasil e a Criação do Conselho de Defesa SulAmericano”. Nueva Sociedad, O Brasil na região. Edição especial em português (Dezembro): 79-89.

Biddle, Stephen B. 1989 The State of Knowledge on the Determinants of the Offensiveness and Defensiveness in Conventional Ground Forces. Alexandria: Institute for Defense Analyses.

Brooks, Stephen G. 1997. "Dueling Realisms”. International Organization 51, no. 3: $445-77$.

Butterfield, Herbert. 1951. History and Human Relations. London: Collins.

Cepik, Marco. 2010. "Segurança regional e integração na América do Sul”. In Segurança Internacional: Práticas, Tendências e Conceitos, edited by Marco Cepik. São Paulo: Hucitec, 2010.

Christensen, Thomas, and Jack Snyder. 1990. "Chain Gangs and Passed Bucks: Predicting Alliance Patterns in Multipolarity”. International Organizations 44, no. 2: $137-68$.

Clausewitz, Carl Von. 1993. On War. New York: Alfred A. Knopf. 
Collins, Alan. 2004. "State-Induced Security Dilemma: Maintaining the Tragedy". Cooperation and Conflict 39, no. 1: 27-44.

Delbrück, Hans. 1990 History of the Art of War (Vol. 4): The Dawn of Modern Warfare. Lincoln: University of Nebraska Press.

Diniz, Eugenio. 2002. Clauserwitz, o Balanço Ataque-Defesa e a Teoria das Relações Internacionais. Rio de Janeiro: UFRJ, mimeo. (Tese de Doutoramento).

Dixit, Avinash, and Susan Skeath. 1999. Games of Strategy. New York: W. W. Norton \& Company.

Duarte, Érico, and Flávio P. Mendes. 2015 “A Ciência da Guerra: Epistemologia e Progresso nos Estudos Estratégicos". Revista Brasileira de Estudos de Defesa 2, no. 2: $129-50$.

Dyson, Tom. 2010; Neoclassical Realism and Defence Reform in Post-Cold War Europe. London: Palgrave Macmillan. Kindle edition.

Elman, Colin. 2004. "Extending Offensive Realism: The Louisiana Purchase and America's Rise to Regional Hegemony". American Political Science Review 98, no. 4: $563-76$.

Farah, Douglas, and Kathryn Babineau. 2019. "Extra-regional Actors in Latin America: The United States is not the Only Game in Town". PRISM 8, no. 1: 96-113.

Fernandes, Adriana, Mateus Vargas, and Tânia Monteiro. 2019. "Bolsonaro exclui Defesa e Ciência de cortes de verba em 2020." O Estado de S. Paulo, caderno de Política. Publicado originalmente em: 6 Dezembro 2019. https://politica.estadao.com.br/noticias/geral,bolsonaro-exclui-defesa-de-cortes-de-verbas-em-2020,70003115532.

Fuccille, Alexandre, and Lucas Rezende. 2013. "Complexo Regional de Segurança da América do Sul: uma nova perspectiva”. Contexto Internacional 35, no. 1 (Janeiro/ Junho): 77-104.

Glaser, Charles L. 1994. "Realists as Optimists: Cooperation as Self-Help". International Security 19, no. 3: 50-90. 1997. "The Security Dilemma Revisited". World Politics 50: 171-201.

Gray, Colin. 1995. "Clausewitz Rules, ok? The Future is the Past — with GPS". Review of International Studies 25, no. 5: 161-82. 
Herz, John H. 1950. "Idealist Internationalism and the Security Dilemma”. World Politics 2, no. 2: 157-80.

Huntington, Samuel P. 1993. "Why Primacy Matters". International Security 17, no. 4: $68-83$.

International Institute for Strategic Studies (IISS). 2014. The Military Balance 114. Jervis, Robert. 1978. "Cooperation under the Security Dilemma”. World Politics 30, no. 2: 167-214.

1999. "Realism, Neoliberalism and Cooperation: Understanding the Debate”. International Security 24, no. 1: 42-63.

2001. "Was the Cold War a Security Dilemma?" Journal of Cold War Studies 3, no. 1: 36-60.

Kennedy, Paul. 1988. The Rise and Fall of the Great Powers: Economic Change and Military Power from 1500 to 2000. London: Unwin Hyman.

Keohane, Robert O., and Lisa Martin. 2003. "Institutional Theory as a Research Program". In Progress in International Relations Theory: Appraising the Field, edited by Colin Elman, and Miriam F. Elman. Cambridge: MIT Press: 71-108.

Labs, Eric J. 1997. "Beyond Victory: Offensive Realism and the Expansion of War Aims”. Security Studies 6, no. 4: 1-49.

Layne, Christopher. 2005. “The 'Poster Child for Offensive Realism': America as a Global Hegemon”. Security Studies 12, no. 2: 120-64.

Lieber, Keir. 2000. "Grasping the Technological Peace: the Offense-Defense Balance and International Security". International Security 25, no. 1: 71-104.

Lima, Maria Regina. 2013. "Relações Interamericanas, a Nova Agenda SulAmericana e o Brasil”. Lua Nova 90, no. 3.

Lynn-Jones, Sean M. 1995. "Offense-Defense Theory and Its Critics". Security Studies 4, no. 4: 660-91.

2001. "Does Offense-Defense Theory has a Future?" GERSI/REGIS Working Paper. www.ciaonet.org/wps/lyso3.pdf.

Malamud, Andrés. 2011. "A Leader Without Followers? The Growing Divergence Between the Regional and Global Performance of Brazilian Foreign Policy". Latin American Politics and Society 55, no. 3: 1-24. 
McNeill, William H. 1982. The Pursuit of Power: Technology, Armed Force, and Society since 1000 A.D. Chicago: University of Chicago Press.

Mearsheimer, John J. 1990. "Back to the Future: Instability in Europe After the Cold War". International Security 15, no. 1: 3-54.

1995. "The False Promise of International Institutions". International Security 19: 4-49. 2001. The Tragedy of Great Powers Politics. New York: Norton \& Company.

Mendes, Flávio P. 2013. Lakatos, o Realismo Ofensivo e o Programa de Pesquisa Científico do Realismo Estrutural. Tese de Doutorado do Instituto de Relações Internacionais da Universidade de São Paulo. São Paulo, $183 f$.

Mijares, Victor. 2016. CINC Dataset Updated: 2008-2013. https://ssrn.com/abstract=2783521 ou http://dx.doi.org/10.2139/ssrn.2783521.

Milner, Helen. 1993. "The Assumption of Anarchy in International Relations". In Baldwin, David A. (Ed.). 1993. Neorealism and Neoliberalism: The Contemporary Debate. New York: Columbia University Press.

Ministério das Relações Exteriores (MRE). 2019. PROSUL. http://www.itamaraty.gov.br/pt-BR/politica-externa/integracao-regional/688-prosul.

Monteiro, Nuno P. 2011/12. "Unrest assured. Why unipolarity is not peaceful". International Security 36, no. 3 (Winter 2011/12): 9-40.

Morgenthau, Hans J. 2003. A Política entre as Nações: A Luta pelo Poder e pela Paz. São Paulo: Editora Universidade de Brasília.

O'Connell, Robert L. 1985. Of Arms and Men: A History of War, Weapons and Agression. New York: Oxford University Press.

Oliveira, Lucas Keer de. 2012. Energia como Recurso de Poder na Política Internacional: Geopolítica, Estratégia e o Papel do Centro de Decisão Energética. Tese de Doutorado do Programa de Pós-Graduação em Ciência Política da Universidade Federal do Rio Grande do Sul. Porto Alegre, 40of.

Orme, John. 1997/1998. "The Utility of Force in a World of Scarcity”. International Security 22, no. 3: 138-67.

Posen, Barry. 1993a. "Nationalism, the Mass Army, and Military Power". International Security 18, no. 2: 80-124. 
$\frac{}{27-47 .}$. 1993b. "The Security Dilemma and Ethnic Conflict". Survival 35, no. 1:

Proença Jr., Domício, Eugenio Diniz, and Salvador G. Raza. 1999. Guia de Estudos de Estratégia. Rio de Janeiro: Jorge Zahar.

Proença Jr., Domício. 2011. "Promessa Tecnológica e Vantagem Combatente". Revista Brasileira de Política Internacional 54, no. 2: 173-88.

Rezende, Lucas P. 2014. “Teoria Realista Ofensiva de Cooperação em Defesa na Unipolaridade”. Contexto Internacional 36, no. 2 (Julho/Dezembro): 519-48.

2015. Sobe e Desce. Explicando a Cooperação em Defesa na América do Sul. Brasília: Editora Universidade de Brasília.

Resende-Santos, João. 2007. Neorealism, States and the Modern Mass Army. Cambridge: Cambridge University Press (Kindle edition).

Rose, Gideon. 1998. "Neoclassical Realism and Theories of Foreign Policy”. World Politics 51, no. 1: 431-64.

Schelling, Thomas C. 1966. Arms and Influence. New Haven: Yale University Press.

Schweller, Randall. 1994. "Bandwagoning for Profit: Bringing the Revisionist State Back In”. International Security 19: 72-107.

1996. “Neorealism's Status Quo Bias: What Security Dilemma?” In Realism: Restatements and Renewal: 90-121, edited by B. Frankel. London: Frank Cass.

. 1997. "Deadly Imbalances: Tripolarity and Hitler's Strategy of World Conquest”. New York: Columbia University Press.

. 2003. "The Progressiveness of Neoclassical Realism”. In Progress in International Relations Theory: Appraising the Field, edited by Colin Elman, and Miriam F. Elman. Cambridge: MIT Press: 311-48.

Schmitt, Carl. 1996. The Concept of the Political. Chicago: University of Chicago Press.

Serbin, Andrés. 2009 "A América do Sul em um mundo multipolar. A Unasul é uma alternativa?" Nueva Sociedad, O Brasil na região. Edição especial em português (Dezembro): 4-16. 
Snyder, Glenn H. 1991. "Alliance Theory: A Neorealist First Cut". In The Evolution of Theory in International Relations, edited by Robert L. Rothstein. Columbia: University of South Carolina.

Snyder, Glenn H. 2002. "Mearsheimer's World: Offensive Realism and the Struggle for Security”. International Security 27, no. 1: 149-73.

Tang, Shiping. 2008. "Fear in International Politics: Two Positions". International Studies Review 10: 451-71.

MacMillan.

2010. A Theory of Security Strategy for Our Time. New York: Palgrave

Taliaferro, Jeffrey W. 2000. "Security Seeking Under Anarchy: Defensive Realism Revisited”. International Security 25, no. 3: 128-61.

Tilly, Charles. 1990. Coercion, Capital and European States: AD 990-1990. Cambridge: B. Blackwell.

Torres, Luísa Fernanda, and Marcella Gomes. 2012. O Conselho de Defesa SulAmericano como Mecanismo de Integração: o Papel do Governo Brasileiro. Anais ABED-PB 2012. ABED, 2012. http://abedpb.org/anais/index.php/2012/article/view/12/13.

Van Evera, Stephen. 1994. "Hypotheses on Nationalism and War". International Security 18, no. 4: 5-39.

. 1998. "Offense, Defense and the Causes of War". International Security 22, no. 4: 5-43.

Vaz, Alcides Costa, Alexandre Fuccille, and Lucas P. Rezende. 2017. "UNASUR, Brazil and the South American defence cooperation: A decade later". Rev. Bras. Pol. Int. 60, no. 2, e012.

Villa, Rafael Duarte. 2017. "Security Community or Balance of Power? Hybrid Security Governance in Latin America”. In Power Dynamics and Regional Security in Latin America, edited by Marcial Suarez, Rafael Duarte Villa, and Brigitte Weiffen. London: Palgrave Macmillan.

Walt, Stephen M. 1987. The Origin of Alliances. Ithaca: Cornell University Press.

Waltz, Kenneth N. 1979. Theory of International Politics. New York: McGraw-Hill. 1981. "The Spread of Nuclear Weapons: More May Better". The Adelphi Papers, 21, no. 171: 383-428. 
. 1988. "The Origins of War in Neorealist Theory”. Journal of Interdisciplinary History 18, no. 4: 615-28.

Wendt, Alexander. 1992. "Anarchy is what States Make of It: the Social Construction of Power Politics". International Organization 46, no. 2: 391-425.

Wohlforth, William C. 1999. "The Stability of a Unipolar World". International Security 24, no. 1 (Summer): 5-41.

2009 "Unipolarity, Status Competition, and Great Power War". World Politics 61, no. 1 (January): 28-57.

Zakaria, Fareed. 1992. "Realism and Domestic Politics: A Review Essay". International Security 17, no. 1: 177-98.

1998. From Wealth to Power: The Unusual Origin of America's Global Role. Princeton: Princeton University Press. 


\section{NOTAS}

1. Para compreender por que a ambiguidade dos meios de força deve ser apreendida a partir de ambas as dimensões (tática e estratégia), ver Diniz (2002).

2. Este argumento é elaborado com mais detalhes em Posen (1993b), retomado abaixo. Para um levantamento e discussão de hipóteses relacionando nacionalismo e guerra, ver Van Evera (1994). Para a previsão de que uma Alemanha desnuclearizada no pós-Guerra Fria, na eventual ausência da Organização do Tratado do Atlântico Norte (Otan), tenderia a compensar esta deficiência pela reincorporação do hipernacionalismo como forma de sustentar um exército de massa, ver Mearsheimer (1990).

3. O argumento de Herz, porém, é anterior a Waltz (1979). No entanto, o evidente papel causal desempenhado pela "sociedade anárquica" (Herz 1950, 157) fornece à discussão de Herz uma base sistêmica, ainda que incipiente.

4. O que não significa que a condição estrutural seja a única explicação possível para a recorrência da competição por poder e o colapso de todos os "megamitos da transformação histórica benigna" (Gray 1999, 166; tradução nossa). Outros realistas têm apontado há tempos para o desejo de dominação do homem sobre o homem, seja por uma condição imanente (Morgenthau 2003), seja pela condição hobbesiana de competição por recursos escassos (Orme 1997), e para a constante capacidade humana de se constituir em grupos que se ameaçam existencialmente pela disposição de matar e morrer em nome daquilo que valorizam (Schmitt 1996). Para uma formulação contemporânea do argumento, ver Gray (1999).

5. Assim como o texto de Herz (1950), o de Jervis (1978) foi escrito antes da obra de Waltz (1979) e, portanto, não possui o mesmo rigor e consistência na caracterização da estrutura política internacional e de seus efeitos sobre o comportamento estatal.

6. A discussão de Jervis também previa a possibilidade de controle consciente da intensidade do dilema da segurança. Por exemplo, diante da eventual capacidade de distinção entre armamentos ofensivos e defensivos - ou, no caso mais comum de emprego dual, que potencializem mais o ataque ou a defesa - , acordos de controle de armamentos poderiam proibir os primeiros e incentivar a aquisição dos segundos. Em teoria, um mundo em que só existissem armamentos exclusivamente defensivos, sem qualquer potencial ofensivo, seria um mundo livre do dilema da segurança (Jervis 1978, 199). Porém, a pergunta natural é: por que razão eles existiriam? Afinal, contra o quê dever-se-ia defen- 
der? De qualquer forma, este mundo, além de livre do dilema da segurança, também deveria necessariamente estar livre da espécie humana, pois, como lembra Mearsheimer (2001), até os braços e pernas de um povo suficientemente motivado podem ser empregados ofensivamente.

7. A viabilidade analítica do balanço ataque-defesa, entretanto, fica abalada diante da crítica clausewitziana. A teoria da guerra de Clausewitz, logicamente assentada no relacionamento entre ataque e defesa, funda-se na realidade material a-histórica da superioridade intrínseca da defesa e de suas manifestações estratégicas: os pontos culminantes do ataque e da vitória. Sendo intrínseca, portanto essencial e inerente à guerra como fenômeno, a superioridade da defesa não é contingente a determinantes tecnológicos de qualquer natureza. Assim, a base lógica do balanço ataque-defesa - ataque e defesa oscilam historicamente como forma mais eficiente de se fazer a guerra - mostra-se insustentável diante da teoria da guerra. A crítica clausewitziana às abordagens do balanço ataque-defesa é construída em Diniz (2002). Críticas semelhantes aparecem em Biddle (1989) e Lieber (2000). Para a defesa das abordagens do balanço ataque-defesa, além de Jervis (1978), ver Van Evera (1998) e Lynn-Jones (1995; 2001).

8. Para a perspectiva que coloca o realismo estrutural não como uma teoria isolada, mas como um programa de pesquisa científica, ver Mendes (2013).

9. Trabalhos comumente associados à proposição revisionista de poder que caracteriza o realismo ofensivo, termo que aparece primeiro na diferenciação de Snyder (1991), incluem, além dos textos de Mearsheimer (1990; 1995; 2001): Zakaria (1992; 1998), Schweller (1994; 1996; 1997), Huntington (1993), Labs (1997), Elman (2004) e Layne (2005).

10. Um argumento similar é levantado por Glaser (1994), que defende a "cooperação como forma de autoajuda".

11. Outros modificadores estruturais incluem: proximidade geográfica, acesso a matérias primas, pressão econômica internacional, balanças militares regionais ou diádicas, e a facilidade com que recursos podem ser extraídos de territórios ocupados (Taliafero 2000, 137).

12. Pode-se argumentar, ainda, que o dilema da segurança é um elemento essencial não só do debate intrarrealista, mas também de debates importantes que opõem o realismo estrutural a outras vertentes teóricas. O debate institucional, por exemplo, tem um componente importante relacionado ao papel de instituições internacionais na mitigação de problemas de segurança na anarquia (Glaser 1994; Mearsheimer 1995; Keohane and Martin 2003; Jervis 1999). O argumento construtivista também pode ser amplamente entendido em torno da origem estrutu- 
ral do dilema da segurança versus sua construção social intersubjetiva (Wendt 1992).

13. A análise restringe-se ao ano limite de 2013 pela indisponibilidade do cálculo dos COW, variável fundamental para seguir a metodologia de Wohlforth $(1999 ; 2009)$ para o cálculo da unipolaridade, após este ano.

14. Sobre o momento transitório, é mister notar que, por mais que a análise material indique um sucateamento das Forças Armadas brasileiras no momento, uma eventual resultante dos programas estratégicos desenvolvidos pelos militares poderia levar a uma rápida melhora na posição relativa do país frente a seus vizinhos. No entanto, ainda que o financiamento desses programas tenha ganhado sobrevida e escapado dos cortes orçamentários promovidos pelo governo Bolsonaro, mesmo com a crise econômica brasileira, (Fernandes, Vargas, and Monteiro 2019) não há garantia que esses programas serão, de fato, bem-sucedidos, ou ainda que não serão contrabalanceados por atores da região. Logo, esta é uma hipótese possível, mas ainda não é nada mais do que isto, o que mantém o aspecto transitório desta análise.

15. A Guiana Francesa não fazia parte da Unasul, por não ser um Estado independente.

16. Por entendermos que é necessário compreender as dinâmicas regionais sul-americanas, este artigo não se propõe analisar o papel dos Estados Unidos, uma vez que seu peso de hegêmona regional do hemisfério ocidental traria um desequilíbrio para a análise. De igual maneira, incluir os EUA demandaria também a inclusão de outros atores extrarregionais como China e Rússia, que têm também atuado na América do Sul como importantes parceiros comerciais e na área de defesa (Farah and Babineau 2019). Desta maneira, evitamos que o artigo se torne, ao cabo, uma análise da balança de poder global, e sim que seja um estudo sobre as dinâmicas políticas e militares exclusivamente dos atores regionais.

17. O índice dos COW parou de ser atualizado em 2008. No entanto, foi possível o uso dos dados atualizados até 2013 pelo trabalho de Mijares (2016). 


\section{RESUMO}

Com foco na América do Sul, discutimos o dilema da segurança demonstrando que não se restringe à mera competição armamentista e tecnológica, perpassando transformações políticas, econômicas e sociais. Ainda que seja comum caracterizar a região como pacífica, sua dinâmica no século XXI não está imune aos efeitos do dilema da segurança.

Palavras-chave: Dilema da Segurança; América do Sul; Teoria de Relações Internacionais; Realismo.

\section{ABSTRACT}

Focusing on South America, we discussed the security dilemma, demonstrating that it is not restricted to mere arms and technological competition, undergoing political, economic and social transformations. Although it is common to characterize the region as peaceful, its dynamics in the 21 st century are not immune to the effects of the security dilemma.

Keywords: Security Dilemma; South America; International Relations Theory; Realism. 